Session 1354

\title{
Invention to Venture: Inspiring Technology Innovation and Entrepreneurship
}

\author{
Phil Weilerstein* and Joseph Steig, David Barbe, Abigail Barrow, \\ Thomas O'Neal, Arnold A. Heggestad, Thomas M. Jacobius \\ National Collegiate Inventors and Innovators Alliance/University of \\ Maryland/University of California, San Diego/University of Central \\ Florida/University of Florida/Illinois Institute of Technology
}

\begin{abstract}
United States colleges and universities have a tremendous untapped entrepreneurial resource in their students and faculty. Despite the emergence of substantial and effective programs in entrepreneurship instruction, ${ }^{1,2,3,4}$ many students who are interested in entrepreneurship, particularly in engineering and the sciences, are not reached through these courses. To address these students' needs, and provide opportunities for building community and connections between the academic and entrepreneurial worlds, a new workshop series has been developed. Invention to Venture (I2 V) is a one-day workshop in technology-driven entrepreneurship for students, faculty, regional entrepreneurs, investors and business leaders. The series is being developed at universities around the country.
\end{abstract}

Invention to Venture is based on several successful models for start-up bootcamps, including the Flight School produced by Joseph Steig for Mass Ventures, a regional technology economic development organization, and the highly successful Technology Startup Boot Camp, conducted for several years at the University of Maryland. The series was further developed by the National Collegiate Inventors and Innovators Alliance (NCIIA) in collaboration with regional partners and consulting firm Grayhead Associates. Invention to Venture provides an opportunity for participants around the country to learn technology entrepreneurship basics, build their networks, and develop plans for moving their ideas forward. The NCIIA and its member institutions intend to make Invention to Venture an effective extracurricular outreach vehicle based at select college campuses across the country. This paper describes the structure, process, and outcomes of the 2003-04 series, which by June 2004 will have reached over 1,500 students, faculty, and other participants at locations from coast to coast.

Proceedings of the 2004 American Society for Engineering Education Annual Conference \& Exposition Copyright $\bullet 2004$, American Society for Engineering 


\section{Background and Overview}

The National Collegiate Inventors and Innovators Alliance (NCIIA) has developed Invention to Venture $(I 2 \mathrm{~V})$, a national series of workshops on collegiate technology entrepreneurship. The goal of Invention to Venture is to stimulate the transformation of the university knowledge base and technical expertise into entrepreneurially generated commercial activity.

$I 2 \mathrm{~V}$ workshops are annual, one-day intensive workshops on technology commercialization and venture creation that take place at host universities throughout the country. The workshop focuses on engineering, science, and technology students and faculty with the intention of extending involvement in the "entrepreneurial enterprise" to a diversity of participants. Members of the local business community are also an important part of the audience. During the first year of the series, over 1,500 emerging technology entrepreneurs will take part in eight or nine workshops. These workshops will become part of a self-sustaining, nationwide series. Invention to Venture workshops provide a high energy introduction to the process and requirements for successful product and venture creation. Participants connect with resources, partners, and programs that can facilitate the pursuit of their entrepreneurial ambitions. The workshops are organized in collaboration with host universities, with guidance and resources provided by the NCIIA. The NCIIA also provides backend and management support, such as a workshop Web site and registration system and curriculum development. The $I 2 \mathrm{~V}$ Summit is a planned annual event that will bring workshop hosts and partner institutions together to network and develop best practices. An advanced workshop planned for year two will bring together a select group of participants for an intensive conference intended to accelerate the technology commercialization process.

The practices established with the initial five workshops have formed the basis for the forum's expansion phase. In the pilot phase, with support from The Lemelson and Kauffman Foundations, each workshop host was given a small seed grant, to be supplemented by additional internal or sponsor funds. This practice will continue, with a smaller grant provided in the second year of the workshop. We expect that by the third year, each workshop will be self-sustaining. Experience from the first five workshops suggests that the grant serves as a "tipping point" that makes the difference between whether or not such a workshop in technology entrepreneurship is established at the host institution. Our expectation is that $I 2 \mathrm{~V}$ will serve as a model for a more aggressive and outward-looking approach to technology entrepreneurship on the part of the nation's research universities — one that actively engages local partners to support emerging entrepreneurs in up to thirty geographic regions of emerging technology innovation.

\section{Informal Entrepreneurship Education as a Collaborative Activity}

The term "innovation enterprise" has been used to describe a collective effort in the country or in 
a region to develop commercially viable innovations. In this paper we use the term "entrepreneurship enterprise" to refer to the collective efforts of individuals and institutions to develop businesses based on technology innovation. We are specifically concerned with the commercialization of university technology through entrepreneurial activity. It is our assessment that in order to be successful in the entrepreneurship enterprise, universities must reach out both within the university and into the surrounding community to individuals and institutions essential to entrepreneurial success. Technology entrepreneurship - while requiring the passion, ambition, and sacrifice of a few individuals - is also a collaborative activity that requires participation from both the university and the surrounding community. $I 2 \mathrm{~V}$ serves both to teach potential entrepreneurs and to engage the community in the entrepreneurial enterprise. ${ }^{5}$ When we say that we expect $I 2 \mathrm{~V}$ to foster a more aggressive and outward looking approach to technology entrepreneurship, we are not only speaking of generalized outreach to the host university's surrounding business community. We are also emphasizing the importance of reaching out to women and minority entrepreneurs, both within and outside the academy. It has been widely noted $^{6}$ that regional support for diversity goes hand-in-hand with entrepreneurial strength.

Many universities have accepted their role as the largest and most visible centers of technology innovation in the regions in which they are located. Fewer have taken on the role as a focal point of the entrepreneurship enterprise in their communities. Invention to Venture is an opportunity for universities to expand their role and position themselves as the active developers of networks of individuals and institutions that can realize the commercial potential of their own cutting edge research. Over time, we expect that collaboration around the $I 2 \mathrm{~V}$ events will play a role in furthering an environment in which the boundaries between various educational, corporate, and economic development entities will become more porous, producing more opportunities for effectively applying the diverse strengths of these institutions and fulfilling their complementary roles in producing innovation.

\section{Participating Institutions}

The first round of Invention to Venture workshops were held at the University of Maryland, University of Central Florida, University of Florida, University of California San Diego, and Illinois Institute of Technology. These five pilot institutions hosted $I 2 \mathrm{~V}$ against the backdrop of established entrepreneurship programs within the institution. Existing offerings range from IIT's Interprofessional Program to University of Maryland's Hinman CEOs and MIPS industrial partnership and incubator programs ${ }^{78910}$, to the Gatornest business incubator at the University of Florida. Each institution brought a unique environment and set of circumstances to Invention to Venture, with particular regional industry strengths. The settings ranged from acknowledged technology hotspots such as the San Diego region to with its extensive network of research institutions, government labs and universities to more isolated locations such as Gainesville, where the host institution is the point of origin for much of the technology commercialization in the area. All participating institutions brought a need to extend entrepreneurship course offerings with $I 2 V$ content. 


\section{The NCIIA}

The activities of the National Collegiate Inventors and Innovators Alliance (http://www.nciia.org/) place it in a unique position to observe the challenges that face the research university in general - and specifically its students and faculty - in the pursuit of their entrepreneurial ambitions. The NCIIA adds value at the nexus of university education and commercial venture development. Established in 1996 and funded primarily by The Lemelson Foundation, the NCIIA is an independently run and funded national program of Five Colleges, Incorporated in Amherst, Massachusetts, itself an educational nonprofit consortium of Amherst, Hampshire, Mt. Holyoke, and Smith Colleges and the University of Massachusetts Amherst. The NCIIA's mission is to advance technological innovation and entrepreneurship in higher education. The NCIIA works on a national basis with technology and business programs at its nearly two hundred member colleges and universities. Through its grants program, it provides resources for curricular development and support for student entrepreneurship teams and their faculty and mentors (E-Teams) working to develop and commercialize technological innovations. The NCIIA also presents conferences and workshops around the country that serve to develop university technology entrepreneurship capabilities.

In the 2003/04 academic year, the NCIIA's grants program will disburse $\$ 1.2$ million to ETeams developing innovative products and technologies, and to faculty developing programs in entrepreneurship and innovation. Through its grants program and other initiatives, the NCIIA provides students with an educational experience based on collaborative, team-based, real-world problem solving with a commercial objective. In doing so, it offers students an opportunity to move from educational exercise to commercial technology development. The Invention to Venture program is a new initiative that goes beyond the NCIIA's existing efforts to fill a gap in technology entrepreneurship education and support—assistance to science and technology students and faculty as they move from educational experience to real world commercialization in a collaborative process, recognizing that engagement with others is essential to success.

Specific Rationale

Technology entrepreneurs have access to a wide variety of learning resources across the country. However, there is no national program that focuses specifically on stimulating the transformation of university research into commercial innovation through entrepreneurship. It is of particular importance to introduce entrepreneurship to science and technology students and faculty. As others have pointed out, if the United States is concerned about shortages of technology professionals in the years ahead, we should be doubly concerned about a shortage of technology professionals who are also schooled in the identification of markets and the commercialization of technology. ${ }^{11}$ Many universities offer "bootcamps," or similar intensive workshops on entrepreneurship. The Technology Start-up Bootcamp offered at the University of Maryland, a well-designed event with several years of history, was used as one of the starting points for planning and development of the $I 2 \mathrm{~V}$ workshop format. The objective was to develop events that 
would encourage the participation of technology faculty along with students, and engage the broader regional technology entrepreneurship community.

Perhaps the best known national "brand" that offers programming for entrepreneurs is the MIT Enterprise Forum. The Enterprise Forum has chapters throughout the country and around the world, and holds intensive entrepreneur bootcamps as well as other workshops. In some locations, events are held on university campuses. Other intensive programs include Garage Technology Ventures Bootcamp and Swing for the Fences, offered through the National Association of State Venture Funds (NASVF). However, these programs do not focus on university students and faculty, and are not focused on the university as the locus of innovation. In addition, they are usually provided to the host institution, rather than developed in association with the host institution, and do not operate with the expectation that the host institution will take ownership of and institutionalize the program over time. Furthermore, there is very little purposeful collaboration across academic institutions located in the same region in organizing and delivering such events, which appears to limit the networking and team building potential that such collaboration can stimulate - among students, faculty, staff, alumni, and the broader entrepreneurial community.

\section{Workshop Structure and Content}

Each $I 2 V$ workshop involves local speakers with expertise and first hand experience in their subject matter. Speakers include successful technology entrepreneurs, venture capitalists, angel investors, marketing consultants, and attorneys. Presentations are typically short and are structured around an outline designed to cover key topics. Host site organizers receive a detailed outline of topics, including suggested speaker profiles and speaker selection guidelines for each area. A typical workshop outline is shown below. More detailed schedule, speaker and content information is available at www.invention2venture.org

9:00 Welcome

9:15 Intro/Background

9:35 Is Technology Entrepreneurship for You?

10:35 Idea and Market Validation

11:45 Lunch with keynote speaker and networking

1:15 Building Teams / Finding the "Right" Friends

1:55 IP \& Licensing Patent Attorney

2:45 Business Plan Panel Discussion

Finding the Money Panel of entrepreneurs/funders

4:05 Closing and Networking Reception

Proceedings of the 2004 American Society for Engineering Education Annual Conference \& Exposition Copyright • 2004, American Society for Engineering 
Pre- and post-workshop surveys and host institution feedback provide useful information about the most important outcomes of the pilot phase of Invention to Venture. We report them here in summarized form.

The first set of Invention to Venture workshops offered a unique opportunity for university students, faculty, and community entrepreneurs to connect with one another, local service providers, and other successful entrepreneurs from around the host regions. Invitations were extended to area universities and businesses, resulting in some cases in attendees that traveled long distances to attend. Campus leaders from various departments and administrative units participated, demonstrating broad campus support for technology innovation and entrepreneurship.

Invention to Venture provided several benefits and opportunities to faculty and students that would not have been possible without the funding and support offered by the NCIIA grant program. Funding, resources, marketing materials, and the NCIIA organizing committee all played a crucial role in the success of each Invention to Venture workshop. By increasing awareness of technology entrepreneurship activity in the host regions, $I 2 \mathrm{~V}$ provided critical next steps required to educate and connect the university community with regional entrepreneurs, business owners, and service providers.

The Invention to Venture Workshop results demonstrated the increasing needs and demand for technology entrepreneurship education. For example, in the UCF community, surveys of participants at the UCF event showed that it attracted a well-balanced group of faculty (13.6\%), graduate students(20.3\%), undergraduate students $(20.3 \%)$, local entrepreneurs, and business owners (11.9\%), and others, including university staff members (10.2\%). Participants represented diverse groups in the community, with over $35 \%$ of respondents describing themselves as members of the Asian, African American, and Latino or Hispanic population. Most UCF attendees (over 50\%) attended because they had a business idea and were most interested in learning about business plan models and developing their business concepts.

$I 2 \mathrm{~V}$ had a significant impact on the UCF audience, familiarizing attendees with many subject areas that were somewhat unfamiliar to them before the event. For example, while less than $4 \%$ of participants at UCF reported that they had an understanding of the path to technology commercialization, over $85 \%$ rated the topic good to excellent in both value and effectiveness. This trend carried through to most of the topical categories covered at $I 2 \mathrm{~V}$. Attendee turnout and responses clearly demonstrate a high, unmet demand at UCF for an event such as Invention to Venture, where faculty and students from across the campus participated in discussion with other entrepreneurs, service providers, and business owners interested in technology entrepreneurship. Over $70 \%$ of UCF participants gave the $I 2 \mathrm{~V}$ workshop an overall excellent rating. 
The University of Florida reported expected additional business plan submissions in the Howard Leonhardt Business Plan Competition as a result of the workshop. Since Invention to Venture, UF also has received additional deal flow and additional student volunteers to Gatornest, its signature incubator program attributable to activities started at the event.

At the University of California at San Diego the organizers reported that without the support and back-room operations supplied by the NCIIA, the von Liebig Center would probably not have attempted such a program so early in its life as it doesn't have all the staffing and resources to efficiently manage such a program. The support from NCIIA in the development of materials and a Web site, and in the management of registration, for example made this a much less daunting task for a young organization that has not yet developed the infrastructure to entirely support such a program on its own.

At all the sites, Invention to Venture introduced faculty and students to entrepreneurship and educated them on the process of technology business creation. The program's length and format enabled both faculty and students to learn about entrepreneurship and technology business formation in a very efficient way. The intense format enabled over-committed faculty who are interested in entrepreneurship to attend and learn enough to know whether they were interested in following such a path themselves. And the program enabled faculty who have just begun creating an entrepreneurial venture to efficiently learn about some of the business issues and terms with which they will have to quickly acquaint themselves. The format enabled students who either have no access to entrepreneurial courses or who are unsure whether they want to dedicate the time such courses require, to get a flavor of some of the issues that need to be considered when starting a technology based company.

While other entrepreneurship training workshops are available, Invention to Venture offers a unique focus on the entrepreneurial educational needs of undergraduate and graduate students, post-docs, researchers, and faculty within the university and research institutions that differentiates it from most other programs. The academic audience feels comfortable seeing other participants like themselves, but also sees that the event attracts "real" entrepreneurs from outside of academe.

Invention to Venture helped increase the on-campus visibility of entrepreneurship programs, positioning the host units in an important place for future campus-wide initiatives. The program increased cross-institution/organization collaboration and recognition, and introduced them to the wider entrepreneurial community. 
Lessons from the Pilot PhaseThe first five $I 2 V$ workshops have been successfully completed ${ }^{12}$. The workshops were developed in partnership with and hosted at five institutions: University of Maryland, College Park; University of California San Diego; University of Central Florida; University of Florida; and Illinois Institute of Technology. The workshops were generally organized through the entrepreneurship programs at each host institution. The all-day events were designed for sophisticated, technology-oriented undergraduate and graduate students and interested faculty and alumni seeking to develop technology-based products and businesses. The program provided a roadmap to tech business plan development, and a venue for technology entrepreneurs to advance their ideas and start their ventures.

Attendance, averaging over two hundred per workshop, was higher than expected at all of the events. The attendee mix at the workshops varied from a majority of students to a broad mix of faculty, students, and community members. The attendance numbers and survey responses confirm that the $I 2 \mathrm{~V}$ workshop fills a distinct need in university communities.

At the time of registration and at the end of each event, attendees were asked to fill out surveys responding to questions about their background, education and career stage, previous exposure to and experiences with entrepreneurship and business, and views on the workshop experience. Survey response rates were good (over 40\%), providing an interesting and useful insight concerning the profile of the audience and their opinions of the event.

Over $42 \%$ of respondents indicated that their motivation for attending $I 2 \mathrm{~V}$ was to learn more in preparation for acting on a business idea (Table 1). Pre- and post-event surveys indicated significant increases in an understanding of what it takes to succeed in technology entrepreneurship. (Table 2) This awareness is a key learning objective of the event and is indicative of success in providing a basic understanding of the process of creating a technology based product or business.

\begin{tabular}{lcc}
\hline Table 1 Reason for Attending Workshop & & \\
\hline $\mathrm{N}=315$, Missing =72 & $\mathrm{N}$ & $\%$ \\
Invited representative of the business community & 31 & $9.7 \%$ \\
Suggested by a professor/advisor & 45 & $14.2 \%$ \\
Seeking new methods of teaching entrepreneurship & 15 & $4.9 \%$ \\
Have business idea & 134 & $42.6 \%$ \\
Part of the student entrepreneurs club & 35 & $11.1 \%$ \\
Other & 55 & $17.5 \%$
\end{tabular}

Proceedings of the 2004 American Society for Engineering Education Annual Conference \& Exposition Copyright • 2004, American Society for Engineering 
As shown in figure 1, overall levels of satisfaction with the workshop were quite high. 94 percent of respondents rated it good or excellent. The levels of satisfaction were uniform across the diverse groups of attendees which included graduate and undergraduate students, faculty as well as community members.

Figure 1 Overall Assessment and Attendee Affiliation

\begin{tabular}{|c|c|c|c|}
\hline Participant Assessment of Workshops & \multicolumn{2}{|c|}{ Average Mix of Workshop Attendance } \\
Undergraduate \\
students \\
$25 \%$
\end{tabular}

Table 2 Knowledge of How to Succeed as a Technology Entrepreneur

\begin{tabular}{lcccc}
\hline & \multicolumn{2}{c}{ Pre-Workshop } & \multicolumn{2}{c}{ Post-Workshop } \\
& \multicolumn{2}{c}{$\mathrm{N}=365$, Missing $=22$} & $\mathrm{~N}=348$, Missing $=39$ \\
Excellent & $\mathrm{N}$ & $\%$ & $\mathrm{~N}$ & $\%$ \\
Good & 23 & $6.4 \%$ & 62 & $17.8 \%$ \\
Fair & 96 & $26.2 \%$ & 223 & $64.1 \%$ \\
Poor & 163 & $44.5 \%$ & 62 & $17.8 \%$ \\
& 83 & $22.8 \%$ & 1 & $0.3 \%$ \\
\hline
\end{tabular}

Proceedings of the 2004 American Society for Engineering Education Annual Conference \& Exposition Copyright • 2004, American Society for Engineering 
Table 3

Steps Toward Entrepreneurship: Before and After Workshop

\begin{tabular}{|c|c|c|c|}
\hline & Now plan & Previously planned & Change \\
\hline $\mathrm{N}=267$ & to Pursue & or Pursued & \\
\hline Start a business & $44.8 \%$ & $74.9 \%$ & $-30.1 \%$ \\
\hline Network in business circles & $66.7 \%$ & $56.6 \%$ & $10.1 \%$ \\
\hline Network in academic circles & $62.0 \%$ & $55.6 \%$ & $6.4 \%$ \\
\hline Attend classes or seminars & $64.1 \%$ & $52.0 \%$ & $12.1 \%$ \\
\hline Join an entrepreneurial club & $49.8 \%$ & $30.2 \%$ & $19.6 \%$ \\
\hline Apply for an NCIIA grant & $54.5 \%$ & $24.3 \%$ & $30.2 \%$ \\
\hline Other & $8.3 \%$ & $2.8 \%$ & $5.4 \%$ \\
\hline
\end{tabular}

The impact of this awareness can be seen in the reduction in the number of attendees intending to start a business in the near term (Table 3). While this may seem like a contradictory result, it is a clear indication that respondents emerged from the workshop with a more realistic understanding of the challenges involved and have adjusted their expectations accordingly. The concurrent increase in reported intentions to learn more-by attending classes and pursuing less structured forms of learning about entrepreneurship — indicates that the workshops had a positive impact on attendees' understanding of how to prepare themselves to create technology based entrepreneurial ventures.

\section{Conclusion}

The results of the pilot series of $I 2 \mathrm{~V}$ workshops have validated the interest in and need for this kind of workshop. Attendees reported high levels of satisfaction and survey results indicated that the workshop is producing the desired increase in interest in pursuing curricular and extracurricular opportunities to create technology based entrepreneurial ventures. Based on these results, we intend to continue to offer the workshop at existing sites and to develop $I 2 \mathrm{~V}$ workshops at additional sites around the U.S., with the objective of informing and energizing thousands of would-be entrepreneurs through intensive workshop experiences that empower them to shape their plans, build a strong team, and achieve their ambitions. 
${ }^{1}$ Marchese, A. J., Shmalzel, J. L., Mandayam S. A., Chen, J.C., “A Venture Capital Fund for Undergraduate Students at Rowan University” Journal of Engineering Education, pp. 589, Volume 90, No. 4, October 2001

${ }^{2}$ Mickle, M.H., Lovell, M., "Brass Rings or Brass Buttons in Engineering Design” Journal of Engineering Education, pp 609. Volume 90, No. 4, October 2001

${ }^{3}$ Sullivan, J.E., Carlson, L.E., Carlson, D.W. "Developing Aspiring Engineers into Budding Entrepreneurs: An Invention and Innovation Course" Journal of Engineering Education, pp. 571,Volume 90, No. 4, October 2001.

${ }^{4}$ Wang, E.L., Kleppe, J.A., “Teaching Invention, Innovation and Entrepreneurship in Engineering” Journal of Engineering Education, pp. 565, Volume 90, No. 4, October 2001.

${ }^{5}$ Commission on Entrepreneurship. 2001. Building Entrepreneurial Networks. Washington, D.C.: National Commission on Entrepreneurship.

${ }^{6}$ Florida, Richard. 2003. "Entrepreneurship, Creativity, and Regional Growth." David M. Hart, Ed. The Emergence of Entrepreneurship Policy, Cambridge University Press.

${ }^{7}$ Barbe, D.F., Thornton, K.S., Magids, S., "Holistic Approach for Technology Entrepreneurship Education in Engineering," Proceedings of the ASEE/IEEE Frontiers in Education Conference, Boulder, CO, November 2003.

${ }^{8}$ Teaching Entrepreneurship to Engineering Students Conference, Monterey, CA, January 2003.

${ }^{9}$ Barbe, D.F., Thornton, K.S., "Components of a Comprehensive Engineering Entrepreneurship Program," Proceedings of the American Society for Engineering Education Annual Conference and Exposition, Montreal, Canada, June 2002, Session 3454, Paper 124.

${ }^{10}$ Barbe, D.F., Thornton, K.S., “Campus Entrepreneurship Opportunities” Proceedings of the American Society for Engineering Education Annual Conference and Exposition, Albuquerque, NM, June 2001, Session 3454.

${ }^{11}$ See Auerswald, Philip E. and Lewis M. Branscomb. 2003.

${ }^{12}$ A sixth workshop in Worcester, Massachusetts was completed as this article was being written. Results from that workshop have not been included in this paper.

\section{DAVID BARBE}

David F. Barbe is Executive Director of the Maryland Technology Enterprise Institute, Professor of Electrical and Computer Engineering and Faculty Director of the CEOs Program. He received B.S. ('62) and M.S. ('64) from West Virginia University and the Ph.D. ('69) from The Johns Hopkins University in Electrical Engineering. He is a Fellow of the IEEE. His publications deal with electronics technology and technology entrepreneurship. He was awarded the ASEE Outstanding Entrepreneurship Educator Award in 2003.

\section{ABIGAIL A. BARROW}

Abigail A. Barrow is the Managing Director of the von Liebig Center at the Jacobs School of Engineering at University of California San Diego. She is a graduate of the University of Edinburgh with a B.Sc. in Mechanical

Proceedings of the 2004 American Society for Engineering Education Annual Conference \& Exposition Copyright • 2004, American Society for Engineering 
Engineering and a Ph.D. in Science Studies. Prior to joining the von Liebig Center, Dr. Barrow undertook research, program development, and program management work for UCSD CONNECT.

\section{ARNOLD A. HEGGESTAD}

Dr. Heggestad is the Holloway Professor of Entrepreneurship and Finance at the University of Florida. He also is the Founding Director of the Center for Entrepreneurship and Innovation. He is currently responsible for the College of Business entrepreneurship program. At the University of Florida since 1974, Dr. Heggestad has served as Chairman, Department of Finance, Insurance and Real Estate; Associate Dean College of Business Administration; Executive Director, University of Florida Research Foundation; and Director of the Division of Entrepreneurial Programs in the Office of Research. He serves on the boards of several Venture Funds and has been involved in multiple startups.

\section{THOMAS M. JACOBIUS}

Tom Jacobius is Director of Interprofessional Studies and The IPRO® Program at Illinois Institute of Technology in Chicago, Illinois. Tom received the B.S. degree in mechanical and aerospace engineering from Illinois Institute of Technology and the Master of Management degree from Northwestern University's Kellogg School of Management with a concentration in marketing. He has established the interprofessional project (IPRO) team course requirement as IIT's signature educational experience for students across all disciplines and professional programs and all academic levels, and involving just as broad a range of faculty expertise.

\section{THOMAS O’NEAL}

Thomas O'Neal is the founder and director of the UCF Technology Incubator and director of sponsored research at the University of Central Florida. An accomplished entrepreneur, O'Neal founded, grew, and sold two ventures before joining UCF. He has a B.S.E.E. from the University of South Florida, an M.S. in engineering management, and an M.B.A. from the University of Central Florida.

\section{JOSEPH STEIG}

Joseph Steig manages the Invention to Venture program for the NCIIA. He has a background in finance and strategic planning and has worked with equity-backed technology companies in a diverse range of industries, including agriculture, environmental technologies, outdoor recreation products, and software. In addition, he has extensive technology economic development consulting experience. Steig also maintains a consulting practice, Innovation Path Inc., working on business and organizational development strategy with technology companies, economic development non-profits, and educational institutions. In this capacity he manages a Massachusetts-based angel investor group, River Valley Investors. Steig has a BA from Hampshire College.

\section{PHILIP J. WEILERSTEIN}

Phil Weilerstein is the Director of the National Collegiate Inventors and Innovators Alliance (NCIIA) a national program designed to encourage and support the incorporation of innovation and entrepreneurship in higher education curriculum. The Alliance is an initiative of The Lemelson Foundation and a program of Five Colleges, Inc. in Amherst, Massachusetts. Mr. Weilerstein received a BS from the University of Massachusetts where as a graduate student he was a co-founder of EcoScience Corporation a publicly held biotechnology company. In addition to his role with the NCIIA he consults in the areas of strategic planning and quality management.

Proceedings of the 2004 American Society for Engineering Education Annual Conference \& Exposition Copyright $\bullet 2004$, American Society for Engineering 